\title{
Concurrent Parasitism Alters Thermoregulation in Honey Bee (Hymenoptera: Apidae) Winter Clusters
}

\author{
MARC O. SCHÄFER, ${ }^{1,2}$ WOLFGANG RITTER, ${ }^{3}$ JEFF S. PETTIS, ${ }^{4}$ and PETER NEUMANN ${ }^{5,6}$
}

\begin{abstract}
Ann. Entomol. Soc. Am. 104(3): 476-482 (2011); DOI: 10.1603/AN10142
ABSTRACT Thermoregulation is crucial for honey bee, Apis mellifera L. (Hymenoptera: Apidae), colony survival in temperate regions, but possible interference by parasites is currently unknown. The small hive beetle, Aethina tumida Murray (Coleoptera: Nitidulidae), and the ectoparasitic mite Varroa destructor Anderson \& Trueman are honey bee parasites and both overwinter in host colonies. The efficiency of thermoregulation might thus be affected in infested host winter clusters, due to altered worker activity. Here, we show for the first time that parasites can alter honey bee thermoregulation. Moreover, the data suggest that only combined infestations with $V$. destructor and A. tumida result in higher thermal maxima in the winter clusters, whereas infestations with one parasite alone had no significant effect compared with the controls. Due to the ubiquitous mite $V$. destructor combined infestations with parasites or combined infections with pathogens are almost inevitable. Therefore, our data indicate that an altered thermoregulation due to multiple infestations might be another widespread factor contributing to winter losses of honey bee colonies.
\end{abstract}

KEY WORDS Aethina tumida, Apis mellifera, thermoregulation, Varroa destructor, winter cluster

Thermoregulation in honey bee colonies, Apis mellifera L. (Hymenoptera: Apidae), is a cornerstone for colony survival in temperate regions (Seeley 1985). A thermal profile of the honey bee colony shows highly stable temperatures in the central core area and concentric isotherms of lower temperatures at distances from the center (Owens 1971, Seeley 1985, Southwick 1985, Stabentheiner et al. 2003). In winter, as the ambient air temperature drops below $15^{\circ} \mathrm{C}$, colonies of European honey bee subspecies form compact clusters to conserve heat. The core temperature is maintained between 18 and $36^{\circ} \mathrm{C}$ (Seeley 1985) through increased metabolic heat production by the core bees (Southwick 1982). As ambient temperature decrease, the bees draw closer together forming a tighter cluster, with a better insulated structure and a steeper temperature gradient from core to periphery (Owens 1971). The outermost bees cool rarely below $9-10^{\circ} \mathrm{C}$, and before they fall into a chill coma, there is mass shifting of bees with the cooler outermost bees moving into the warm central area (Southwick 1985).

The ectoparasitic mite Varroa destructor Anderson $\&$ Trueman is the most serious pest of European honey

${ }^{1}$ Institute of Infectology, Friedrich-Loeffler-Institute (FLI), Federal Research Institute for Animal Health, 17493 Greifswald-Island Riems, Germany.

${ }_{2}$ Corresponding author, e-mail: marc.schaefer@fli.bund.de.

${ }^{3}$ Institute for Chemical and Veterinary Research (CVUA), D-79108

Freiburg, Germany.

${ }^{4}$ USDA-ARS Bee Research Laboratory, Beltsville, MD 20705.

${ }^{5}$ Swiss Bee Research Centre, Agroscope Liebefeld-Posieux Research Station ALP, CH-3003 Bern, Switzerland.

${ }^{6}$ Department of Zoology and Entomology, Rhodes University, Grahamstown 6140 , South Africa. bees worldwide (Ellis and Munn 2005). Due to the ubiquitous nature of this mite, multiple infestations with parasites or infections with pathogens are inevitable. The mites reproduce in association with honey bee brood (Sammataro et al. 2000), but they are also able to survive on adults alone (=phoretic phase; Schulz 1984). Indeed, winter clusters can contain a considerable proportion of $V$. destructor on adult workers (0.23-0.51 mites per bee; Ritter et al. 1989). The mite also seems to play a central role for the high recent colony losses in the United States and Europe (De la Rúa et al. 2009, Rosenkranz et al. 2010). Moreover, honey bee workers emerging from mite-infested cells do not fully develop physiological features typical of long-lived winter bees compared with noninfested workers (Amdam et al. 2004). Those workers do not accumulate hemolymph proteins, including vitellogenin, to the same extent as workers emerging from cells free of $V$. destructor (Amdam et al. 2004). In addition to other detrimental effects on adult workers due to mite infestation in the pupal stage (e.g., weight loss, deformity, reduced life span; cf. Ball 1994), another potential mechanism might be that heavily miteinfested colonies are less able to regulate temperature. However, to our knowledge, the potential effect of $V$. destructor on thermoregulation in winter clusters has not been investigated.

The small hive beetle, Aethina tumida Murray (Coleoptera: Nitidulidae), is a parasite and scavenger of honey bee colonies, native to sub-Saharan Africa (Lundie 1940, Hepburn and Radloff 1998, El-Niweiri et al. 2008, Neumann and Ellis 2008). Small hive beetles managed to establish populations in the United States and 


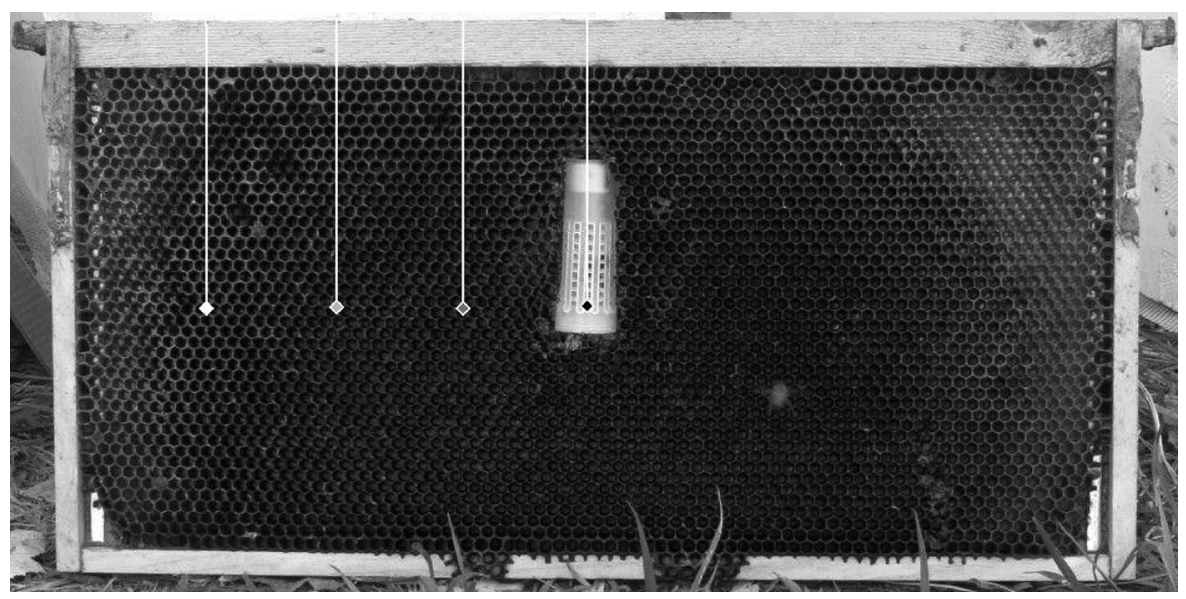

Fig. 1. Empty comb with an embedded queen-cage in the center. White lines symbolize four thermal sensors at particular positions that measured the temperature at 2-min intervals.

Australia (Neumann and Ellis 2008), where they infest colonies of European honey bee subspecies (Neumann and Elzen 2004). Honey bee workers are usually not able to kill or eject adult small hive beetles due to their hard exoskeleton and their defensive behavior (Neumann et al. 2001). Therefore, it is very likely that the beetles can intrude and remain inside winter clusters, especially because overall activity of the bees is obviously constrained by the cold ambient temperature. Indeed, A. tumida does overwinter in the United States inside the winter cluster (Hood 2000, Schäfer et al. 2010). Occasionally, even $>300$ small hive beetles were found in the center of winter clusters (Pettis and Shimanuki 2000). Due to their exoskeleton and their defensive behavior, we hypothesize that adult small hive beetles inside a colony will be able to invade the cluster, even when the ambient temperature quickly drops (e.g., due to cold snap blizzards). Indeed, even if a relatively high proportion of adult small hive beetles could not survive the winter in field colonies (83.6\% mortality), a notable amount stayed alive (Schäfer et al. 2010). For their survival inside clusters, small hive beetles must be able to feed on honey and to find areas with sufficient temperature for survival. With respect to the spatial distribution of adult small hive beetles within the rather small artificially established clusters, because beetles should prefer warmer areas, we predict that the majority of introduced small hive beetles would be found in the core areas of the clusters. This however has yet to be investigated. Because adult honey bee workers very often actively react to adult beetles (Elzen et al. 2001, Neumann et al. 2001), we expect that the sheer presence of small hive beetles (Ellis et al. 2003), the movement of beetles within the cluster as well as begging for food (Ellis et al. 2002) may disturb normal bee activity. This additional activity of workers resulting from the presence of adult small hive beetles could interfere with normal cluster activity. Therefore, we expect that winter clusters with small hive beetles, may show higher thermal maxima and the temperature inside the clusters might be less stabile (=higher thermal fluctuations) compared with those in noninfested colonies.
Higher temperatures and/or thermal fluctuations imply higher activity and therefore higher metabolic rates of the workers and increased consumption of honey stores (Ritter 1982). In colonies that are infested by $V$. destructor, A. tumida, or both, the parasites overwinter within the honey bee cluster. These inquiline parasites might influence thermoregulation of the clustering bees and therefore could have an impact on the overwintering success of the colonies.

We hypothesize, that the activity inside honey bee clusters increases, when bees are infested with $V$. destructor or A. tumida. Here, we investigate the possible impact of $V$. destructor and $A$. tumida infestations on thermoregulation in winter clusters by using groups of honey bee colonies that are exposed to different infestation levels with both parasites under experimental conditions inside a cold room $\left(-5^{\circ} \mathrm{C}\right)$. We also assess whether simultaneous infestations with both parasites result in even greater effects on thermoregulation and monitored spatial distribution of $A$. tumida within winter clusters which, to our knowledge, has not yet been investigated.

\section{Materials and Methods}

Experimental Design. The experiments were conducted in November 2007 at the USDA-ARS Bee Research Laboratory in Beltsville, MD. To test for the impact of infestations with $V$. destructor and A. tumida on overwintering, we established four groups of nucleus colonies inside a cold room at $-5^{\circ} \mathrm{C}$, which were exposed to different infestation levels: 1) control ( $[\mathrm{C}] ; n=10), 2)$ A. tumida infestation ( $[\mathrm{A}] ; n=10)$, 3) $V$. destructor infestation ( [V];n=10) and 4) concurrent infestation with A. tumida and V. destructor ( $[\mathrm{AV}] ; n=10)$. Each colony was placed in a wooden five-frame nucleus box with screened bottom and lid (mesh width, $1 \mathrm{~mm}$ ) and consisted of three combs and $400 \mathrm{~g}$ of honey bees $(\approx 4,000$ bees $)$. The middle comb had empty cells and a mated, caged queen in its center (Fig. 1). We caged the queens to 


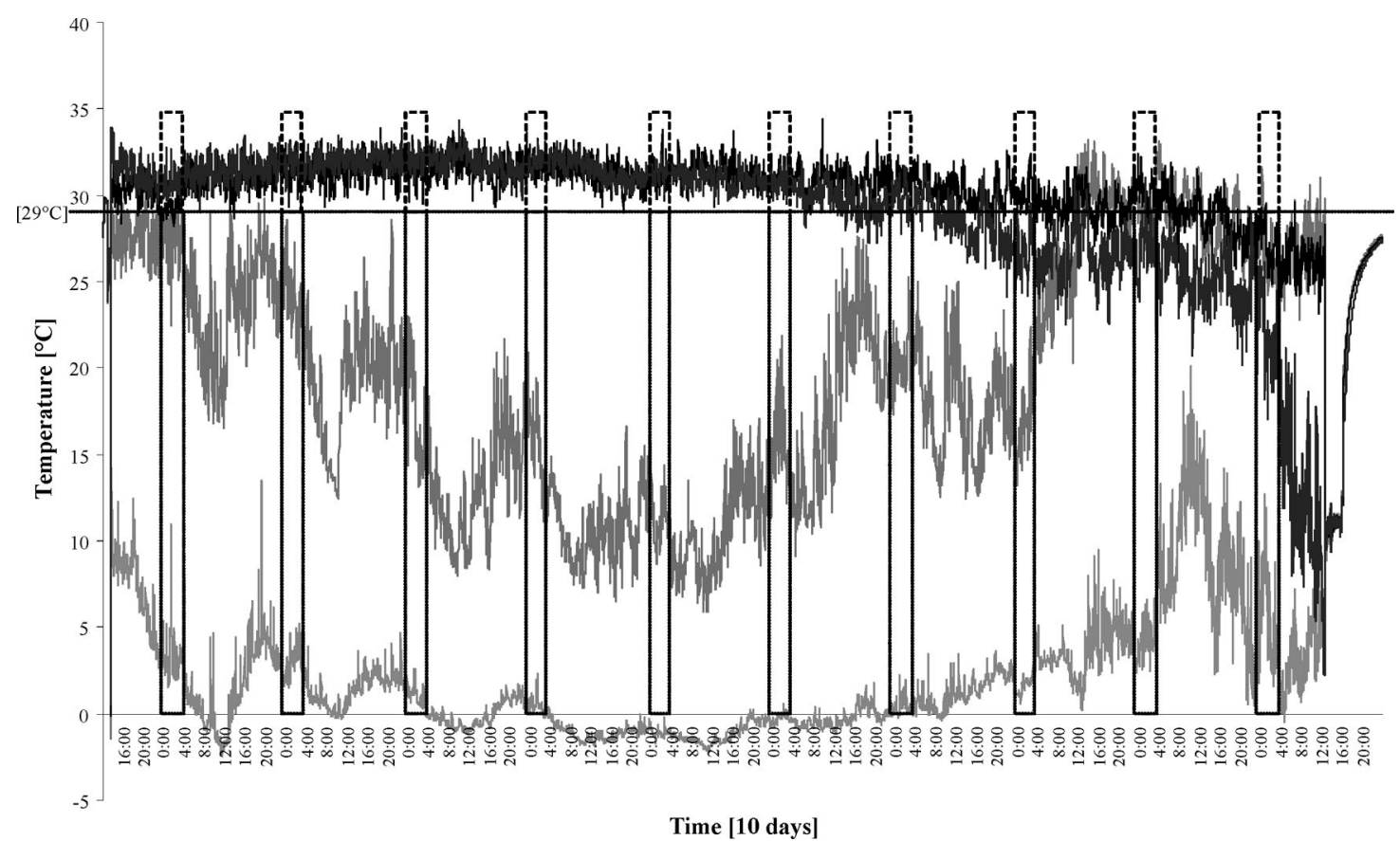

Fig. 2. Example for the process of temperature, measured at four fixed positions (see Fig. 1), in a cluster of honey bees at $-5^{\circ} \mathrm{C}$ over a $10-\mathrm{d}$ period. The dashed lines represent the thermal sets (measured temperatures from 12 a.m. to 4 a.m. that had means of $\geq 29^{\circ} \mathrm{C}$ ) for calculation of thermal fluctuations in the center of the clusters. Only temperature sets from 12 a.m. to $4 \mathrm{a} . \mathrm{m}$. that had means of $29^{\circ} \mathrm{C}$ or above were used. The gray scale values of the lines are equivalent to particular positions of thermal sensors inside the colony. The darker the gray, the closer to the center of the colony, as shown in Fig. 1.

ensure broodless clusters and to fix the clusters in the central area, where thermal sensors were located, because it was shown that the queen stays always in the central area of the cluster and indicates the warmest spot in broodless colonies (Ritter 1982). The middle comb was surrounded by two combs with capped honey. All honey bees were of mixed European origin. The mated queens were obtained from Hawaii (Kona Queen Hawaii, Inc., Kona, HI) and embedded into the combs just before the workers were added. To facilitate queen acceptance, the cages were coated with honey. The workers originated from two apiaries, which differed in their infestation levels with $V$. destructor. Due to treatments against $V$. destructor (with Apiguard, one cup per colony in the end of July 2007 and another cup $2 \mathrm{wk}$ later, according to the manufacturers' directions; the active ingredient per cup is $12.5 \mathrm{~g}$ thymol $)$, the colonies at the first apiary $(n=8)$ were relatively free of $V$. destructor infestation (sticky boards 24 h, 0 mites; Sammataro et al. 2002), whereas the colonies $(n=13)$ at the second apiary had not been treated for $>1 \mathrm{yr}$ and had correspondingly high infestation with $V$. destructor (sticky boards $24 \mathrm{~h}$, $85.6 \pm 32.3$ mites). The workers from each apiary were pooled separately to eliminate the potential influence of different genetic backgrounds of the source colonies. For this purpose, the queens of all colonies were captured and removed at both apiaries, $1 \mathrm{~d}$ before the start of the experiment to expedite colony manipulation the next day. The next day, starting with the noninfested colonies from the first apiary, all bees $(\approx 12 \mathrm{~kg}$ ) were shaken from combs into a screened box ( 1 by 1 by $1 \mathrm{~m}$ ) and mixed carefully. Then, similar partitions of those bees ( $400 \mathrm{~g}$ each) were transferred into nucleus boxes $(n=20)$, which were already fully equipped with broodless combs and caged new queens $(\rightarrow$ groups, $\mathrm{C}$ and $\mathrm{A})$. Afterward, the same procedure was repeated with the $V$. destructor infested bees from the second apiary ( $\rightarrow$ groups, V and AV). From the mixed $V$. destructor infested bees, four samples were taken in alcohol $(\approx 400$ bees each) to evaluate the $V$. destructor infestation load via the mite/bee ratio (De Jong et al. 1982a). Furthermore, all colonies of groups AV and A were infested with 100 adult small hive beetles each, by adding them onto the top bars, directly after the bees were transferred into their boxes. The adult small hive beetles were reared in the laboratory according to standard procedures (Mürrle and Neumann 2004).

Directly after bees and where applicable, small hive beetles were added, the colonies $(n=40)$ were closed with a screened lid and transferred into a cold room at $-5^{\circ} \mathrm{C}$ and constant darkness. The next day, four thermal sensors were carefully inserted in the bee clusters through the screened lid, in each colony at similar positions (Fig. 1) and then connected to data loggers $(n=40)$, recording the temperature at 2-min intervals over $10 \mathrm{~d}$ (Fig. 2).

To define the spatial distribution of adult A. tumida and $V$. destructor inside the clusters, all colonies were killed after $10 \mathrm{~d}$ by dipping the nucleus (immediately 
after taking them out of the cool room) into liquid nitrogen for $1 \mathrm{~min}$ to keep the structure of the cluster. Then, all colonies were stored in a cold room until they were carefully dissected (all frames, bees, and small hive beetles were removed). All bees inside cells were removed to investigate the cell-bottoms. For each detected small hive beetle, the position was recorded as follows: core (=central area of clusters; $\varnothing=7 \mathrm{~cm}$ ), inside queen cages; periphery (=cluster, except core area), and outside clusters on the comb or elsewhere inside the nucleus. Two bee samples in alcohol were taken from each colony $(\approx 150$ bees from the core area and $\approx 250$ bees from the periphery) to compare their mite/bee ratio (De Jong et al. 1982a).

Data Analysis. For the calculation of thermal fluctuation and thermal maxima, only measured temperatures from 12 a.m. to 4 a.m. were taken, because lower metabolic rates are expected during the night (Southwick 1982, 1983), where fewer activities influence thermoregulation (Ritter 1982). The circadian metabolic rhythm persists under constant darkness and is apparent in colonies with or without brood (Moritz and Southwick 1992). The standard deviation and the maxima of each temperature set (measured temperatures from 12 a.m. to 4 a.m.) were calculated for each sensor. The higher the standard deviation of a temperature set, the higher the thermal fluctuation at this particular sensor. To select for thermal fluctuations and thermal maxima in the core area, only those temperature sets were used, which had means of $\geq 29^{\circ} \mathrm{C}$ (= average body-surface-temperature of core bees in broodless winter clusters; Stabentheiner et al. 2003). All calculated standard deviations were assigned to their related groups (C, $\mathrm{A}, \mathrm{V}$, and $\mathrm{AV}$ ), and were then compared by KruskalWallis tests and multiple post hoc Mann-Whitney $U$-test comparisons (Bonferroni adjusted, $\alpha=$ $0.013)$. Also, all temperature set maxima were assigned to the related groups $(\mathrm{C}, \mathrm{A}, \mathrm{V}$, and $\mathrm{AV})$, but because these data sets were parametric $(P=0.98$; Levene's test) they were compared by analysis of variance (ANOVA) followed by multiple post hoc Bonferroni comparisons. The amplitudes $(A)$ of the thermal fluctuations were calculated by subtracting the recorded minimum temperature from the maximum temperature of each temperature set.

The quantities of small hive beetles inside clusters were compared between the groups A and AV by MannWhitney $U$-tests and their spatial distribution within the clusters by Friedman's ANOVAs, followed by Wilcoxon's matched-pairs tests for post hoc comparisons (Bonferroni adjusted, $\alpha=0.025)$. Furthermore, the Kolmogorov-Smirnov test was applied to determine whether both data sets (A and AV) differ significantly. Within the groups $\mathrm{V}$ and $\mathrm{AV}$ the mite/bee ratios were compared between core and periphery by using Wilcoxon's matched pairs tests and between the groups by MannWhitney U-test. Proportions of small hive beetle and mite/bee ratios are given as medians (first, third quartiles).

\section{Results}

At mean temperatures $\geq 29^{\circ} \mathrm{C}$, the groups showed significantly different amplitudes $(A)$ in thermal fluctuations inside the clusters, which were expressed in standard deviations of the temperature sets (KruskalWallis test: $\mathrm{H}[3, n=177]=17.42, P<0.01)$. Both groups infested with $V$. destructor mites $(\mathrm{V}$ and $\mathrm{AV}$, mite/ bee ratio $=0.20 \pm 0.03$ ) had higher $A$ values than those groups, which were relatively free of $V$. destructor (C and A) (Fig. 3). Thermal fluctuations of the small hive beetle-infested group $\mathrm{A}\left(\mathrm{A}=3.6 \pm 1.1^{\circ} \mathrm{C}\right)$ were significantly lower than in the double-infested group $\mathrm{AV}\left(P=0.03, A=4.6 \pm 2.1^{\circ} \mathrm{C}\right)$ and in the $\mathrm{V}$. destructor-infested group $\mathrm{V}(P<0.01, A=4.6 \pm$ $\left.1.1^{\circ} \mathrm{C}\right)$. There were no differences in thermal fluctuation between the two groups infested with $V$. destructor ( $\mathrm{V}$ and $\mathrm{AV}, P=1.00)$. Likewise, there were no differences between the control $\left(\mathrm{C} ; A=4.0 \pm 1.5^{\circ} \mathrm{C}\right)$ and any of the other groups $(\mathrm{C}$ and $\mathrm{A}, P=0.38 ; \mathrm{C}$ and $\mathrm{V}, P=0.06$; and $\mathrm{C}$ and $\mathrm{AV}, P=0.90)$.

Among the thermal maxima of all temperature sets (means $\geq 29^{\circ} \mathrm{C}$ ) in the four experimental groups were significant differences between the groups (ANOVA: $F[3, n=177]=4.06 ; P=0.01$ ) (Fig. 4). Maxima in the double-infested group AV were significant higher compared with control group $\mathrm{C}(P=0.01)$ and the $A$. tumida-infested group A $(P=0.02)$. There were no significant differences in thermal maxima between the other groups ( $\mathrm{V}$ and $\mathrm{AV}, P=0.61 ; \mathrm{C}$ and $\mathrm{A}, \mathrm{C}$ and $\mathrm{V}$, and $\mathrm{A}$ and $\mathrm{V}, P=1.00)$.

From the introduced small hive beetles (100 per colony), $7.5(3.5,19.3)$ were found inside the clusters. The rest was either found on the bottom-screens (89.0 [80.0, 93.0]) or outside the clusters on the combs (3.5 [1.0, $5.0])$. In the core area of small hive beetle-infested clusters, many worker bees were inside cells, whereas almost all small hive beetles were found in-between the clustering bees. Only in one occasion, a single small hive beetle was found underneath a bee on the bottom of a cell. There were no significant differences in quantity of small hive beetles inside clusters between both small hive beetle-groups (A and AV; Mann-Whitney $U$-test: $\mathrm{U}=29$, $P=0.11$; Kolmogorov-Smirnov test: $P=0.31$ ), even though a slightly higher number of small hive beetle was found in the double-infested clusters $(\mathrm{A}=5.0[0.3,16.3]$ and $\mathrm{AV}=14.0[6.3,23.8])$. In all 10 colonies of the AV group, adult small hive beetles were found in the clusters, whereas in three of the $10 \mathrm{~A}$-group colonies, the clusters were free of small hive beetles. There were significant differences in the proportions of small hive beetles inside clusters between periphery, core and cage in both groups (Friedman ANOVAs: A: $\chi^{2}[2, n=10]=6.33, P=0.04$ and $\left.\mathrm{AV}: \chi^{2}[2, n=10]=7.37, P=0.03\right)$. In the peripheries of the AV-group clusters, significantly more small hive beetles were found compared with the cores (Wilcoxon's test [Bonferroni adjusted, $\alpha=0.025]$ : $P=0.02$ ). However, there were no further significant differences between the other distributions within the clusters (Wilcoxon's test [Bonferroni adjusted, $\alpha=0.025]$ : AV: periphery-cage: $P=$ 0.58 , core-cage: $P=0.05$ and A: periphery-core: $P=0.04$, periphery-cage: $P=0.40$, core-cage: $P=0.04$ ). The spatial 


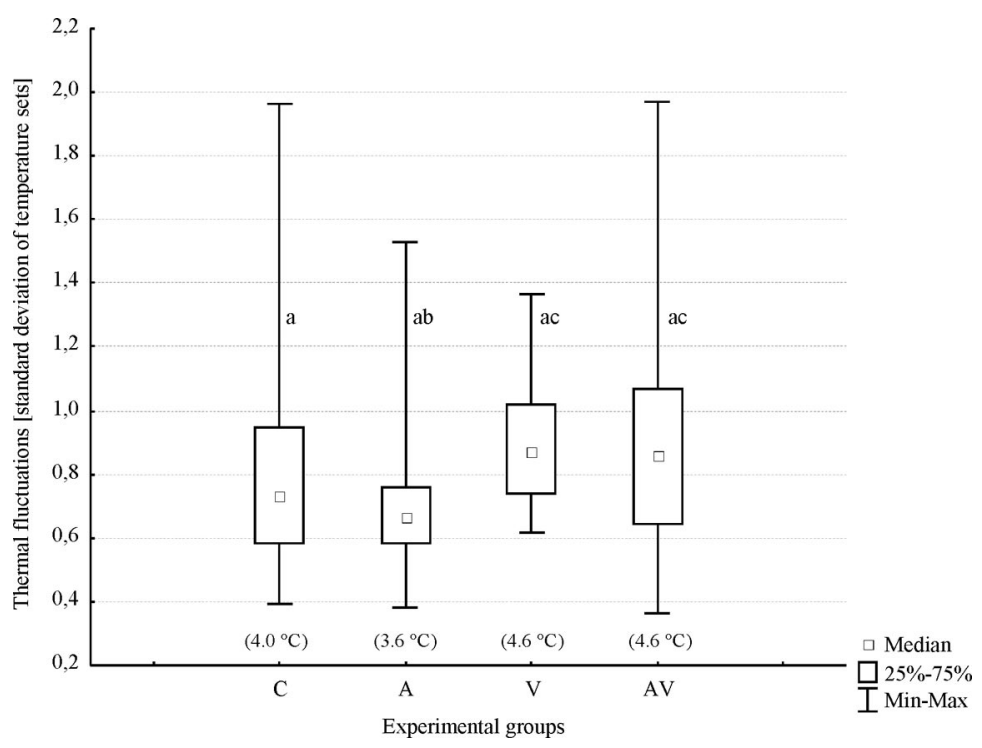

Fig. 3. Thermal fluctuations in four experimental groups, shown as standard deviations of the respective temperature sets with means of $\geq 29^{\circ} \mathrm{C}$ inside the clusters. Over all groups, significant differences in thermal fluctuation were found (KruskalWallis test: $\mathrm{H}[3, n=177]=17.42 ; P<0.001$ ). The mean amplitudes (maximum-minimum temperature of a set) of each group are given in the figure in parentheses. Thermal fluctuations in A. tumida-infested group (A) were significant lower compared with the double-infested group $(\mathrm{AV} ; P=0.025)$ and the $V$. destructor-infested group $(\mathrm{V} ; P<0.001)$. There were no significant differences in thermal fluctuations between other groups. C, control; A, A. tumida infested; V, V. destructor infested; AV, double infested. Different letters in the figure indicate significant differences.

distributions of small hive beetles within clusters were A, $0.5(0.0,3.8)$ in periphery; $0.0(0.0,0.0)$ in core; and $1.5(0.0$, $7.5)$ in cage and AV, $2.0(1.0,3.8)$ in periphery; $0.0(0.0,1.8)$ in core; and $4.0(1.3,10.5)$ in cage.

There were no differences in the mite/bee ratio between core $(0.08[0.05,0.10])$ and periphery $(0.06[0.05$, $0.08]$ ) in both $V$. destructor-infected groups (Wilcoxon's

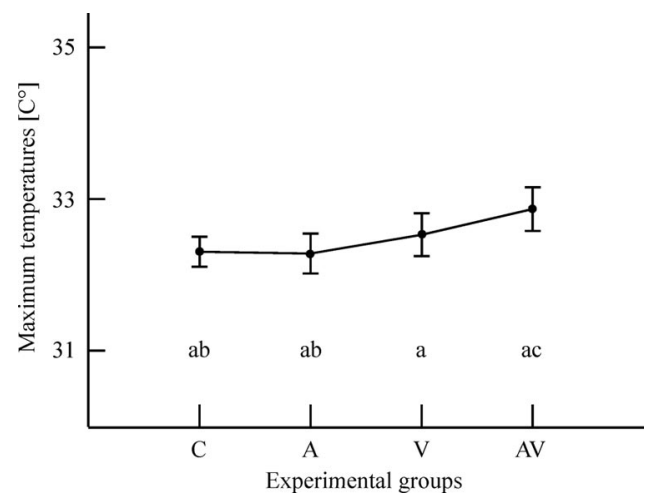

Fig. 4. Thermal maxima of all temperature sets with means $\geq 29^{\circ} \mathrm{C}$, for four experimental groups. Over all groups, significant differences were found (ANOVA: $F[3, n=177]=4.06 ; P=$ $0.008)$. Maxima in the double-infested group (AV) were significant higher compared with the control group $(\mathrm{C} ; P=0.011)$ and the A. tumida-infested group $(\mathrm{A} ; P=0.020)$. There were no significant differences in thermal maxima between other groups. C, control; A, A. tumida infested; V, V. destructor infested; AV, double infested. Different letters in the figure indicate significant differences. test: $\mathrm{V}, P=0.17$ and $\mathrm{AV}, P=0.17)$. Likewise, no differences in the mite/bee ratio were found between both groups (Mann-Whitney $U$-test: $\mathrm{U}=168, P=0.39$ ).

\section{Discussion}

Our data clearly show that simultaneous infestations with two parasites can significantly affect thermoregulation of honey bees in the winter cluster. Indeed, although infestations with a single parasite had no significant effect compared with the controls, infestations with both A. tumida and V. destructor resulted in significantly higher core maximum temperatures. This strongly suggests that interactions between these parasites may have side effects on overwintering colonies, which have not yet been documented. Furthermore, infestations with both parasites or with $V$. destructor alone resulted in significantly higher thermal fluctuations compared with infestations with A. tumida alone, which underlines the high probability that $V$. destructor plays a major role for the recently observed higher colony losses.

Even under the extreme conditions in our test, where the introduced beetles had to withstand and respond to a rapid and considerable decrease in temperature $\left(-5^{\circ} \mathrm{C}\right.$ compared with $25^{\circ} \mathrm{C}$ outside temperature), $11.6 \%$ of the introduced small hive beetles were able to invade the clusters. However, future experiments on the success rate of cluster invasion by small hive beetles might decrease the temperature more slowly to better mimic the natural process from fall into winter. It seems as if the small hive beetles were searching for relatively undisturbed positions in 
the heated cores of the clusters, because $54.1 \%$ of the intruded beetles were found inside the queen cages, which were inaccessible for workers. Therefore, those cages provided shelter from bee aggression (Elzen et al. 2001) and the cages probably offered good opportunities for small hive beetles feeding by the workers (Ellis et al. 2002), because workers are continuously feeding queens. Although these cages represent an unnatural shelter and under natural conditions such aggregations of small hive beetles near the queen may happen at higher small hive beetle populations only, these small hive beetles inside the cages reflect stress and disturbance in infested colonies, because they could lead to stress among the queen feeding bees, which were probably tricked and disturbed by food begging beetles. Outside those cages, only small proportions of small hive beetles were found in the center. It seems as if once inside the cluster, small hive beetles tend to avoid the rather active core-bees and prefer the periphery, unless queen cages offer suitable shelter. Indeed, outside of queen-cages, a significantly higher fraction of small hive beetles was found in the peripheries of the $V$. destructor infested clusters compared with their centers. There were no significant differences in quantities of small hive beetles within clusters between colonies with or without $V$. destructor infestation $(P=0.11)$, nor were there significant differences in the data distribution between these two groups $(P=0.31)$. For $V$. destructor, there were no differences in mite/bee ratios between periphery and core in both $V$. destructor-infested groups.

The data clearly show that only infestations with both A. tumida and V. destructor did significantly increase maximum temperatures inside winter clusters compared with the controls. Why is the combination important and not one parasite alone? This might be related to interactions between the different effects of the two parasite species. The main impact of $V$. destructor is probably due to altered physiology of winter bees emerging from mite-infected cells (Amdam et al. 2004). Indeed, workers that were infested during their pupal stage do not fully develop the physiological features, which are typical of the long-lived winter bees (Amdam et al. 2004). Moreover, such bees show a reduction in body weight (De Jong et al. 1982b) and longevity (Kovak and Crailsheim 1988). The observed higher thermal fluctuations in both groups infested with $V$. destructor ( $\mathrm{V}$ and $\mathrm{AV}$ ) compared with the group only infested with A. tumida may be related to these physiological alterations.

From a behavioral point of view, the phoretic mites also might contribute. Indeed, phoretic mites elicit grooming behavior of parasitized workers including general unrest, cleaning movements, grooming dance of infested bees and nest mate cleaning (Ruttner and Hänel 1992). Likewise, adult small hive beetle induce behavior in workers, such as aggression and trophallactic feeding (Elzen et al. 2001, Ellis et al. 2002, Neumann and Elzen 2004). Workers do recognize small hive beetles very easily and often react fiercely (Elzen et al. 2001). Moreover, the adult beetles are larger than phoretic $V$. destructor mites, and thereby more likely to interfere in the densely packed winter clusters. It seems therefore safe to assume that the behavioral changes of workers in the densely packed winter clusters induced by A. tumida are considerable more pronounced compared with phoretic mites $V$. destructor. The density of the clustering bees and especially the insulating periphery of the cluster could be affected by this behavioral interference. Despite that there were no significant differences in numbers of small hive beetles per cluster between the two beetle-infested groups, there were slightly higher small hive beetle numbers in the double-infested clusters. In a field test in Georgia and South Carolina it was shown, that average $V$. destructor numbers per colony decreased as apiary A. tumida levels increased (Delaplane et al. 2010). In contrast, one could assume that the ability of the workers to suppress small hive beetles entering the cluster could be lowered by $V$. destructor, which actually may be another effect of concurrent infestation by theses two parasites. Our experimental design clearly does not allow differentiating between the importance of altered physiology of winter bees due to $V$. destructor infestation versus altered behavior due to the presence of phoretic mites and overwintering adult beetles. However, the combination of both physiological and behavioral changes in the winter bees in colonies infested by both parasites seem to push the system to a critical point which leads to the significant higher thermal maxima in the winter clusters.

What are the potential consequences of such an increased cluster temperature? Although the observed differences in thermal maxima are not high, they will certainly create higher metabolic rates, which will add up over the course of the winter. If an increased cluster temperature results in an expanded active center, it could lead to higher and longer brood activity of infested colonies with potential side effects on $V$. destructor reproduction. Moreover, higher temperature would promote replication of Nosema spp. in adult bees (Ritter 1996). Furthermore, an expanded core zone would increase heat loss of the cluster (Southwick 1983). Resulting higher metabolic rates could not only induce an increase in honey consumption of a colony (thus reducing colony honey stores faster) but also increase oxidative stress, thereby leading to behavioral senescence and a reduced longevity (Williams et al. 2008).

In conclusion, our data suggest that induced changes in colony thermoregulation by dual parasitism might constitute another factor contributing to winter losses in honey bee colonies.

\section{Acknowledgments}

We thank Stephan Härtel, Samuel Abban, Josephine Johnson, Victor Levi, Nathan Rice, and Andrew Ulsamer for providing technical and field assistance that contributed much to the success of the project. We thank Maxcy P. Nolan, IV, and William M. Hood for providing small hive beetles for our laboratory rearing. We also thank Mark Greco, who ameliorated the writing. Financial support was granted to M.O.S., W.R., and P.N. by the German Federal Ministry for Food, Agriculture and Consumer Protection through the Federal Agency for Agriculture and Food and by the USDAARS Areawide Project on honey bee health to J.S.P. 


\section{References Cited}

Amdam, G. V., K. Hartfelder, K. Norberg, A. Hagen, and S. W. Omholt. 2004. Altered physiology in worker honey bees (Hymenoptera: Apidae) infested with the mite Varroa destructor (Acari: Varroidae): a factor in colony loss during overwintering? J. Econ. Entomol. 97: 741-747.

Ball, B. V. 1994. Host-parasite-pathogen interactions, pp. 5-11. In A. Matheson (ed.), New perspectives on varroa. International Bee Research Association, Cardiff, United Kingdom.

De Jong, D., D. De Andrea Roma, and L. S. Gonçalves. 1982a. A comparative analysis of shaking solutions for the detection of Varroa jacobsoni on adult honeybees. Apidologie 13: 297-306.

De Jong, D., P. De Jong, and L. S. Gonçalves. 1982b. Weight loss and other damage to developing worker honeybees from infestation with Varroa jacobsoni. J. Apic. Res. 21: 165-167.

De la Rúa, P., R. Jaffé, R. Dall'Olio, I. Muñoz, and J. Serrano. 2009. Biodiversity, conservation and current threats to European honeybees. Apidologie 40: 263-284.

Delaplane, K. S., J. D. Ellis, and W. M. Hood. 2010. A test for interactions between Varroa destructor (Acari: Varroidae) and Aethina tumida (Coleoptera: Nitidulidae) in colonies of honey bees (Hymenoptera: Apidae). Ann. Entomol. Soc. Am. 103: 711-715.

Ellis, J. D., and P. A. Munn. 2005. The worldwide health status of honey bees. Bee World 86: 88-101.

Ellis, J. D., C.W.W. Pirk, H. R. Hepburn, G. Kastberger, and P. J. Elzen. 2002. Small hive beetles survive in honeybee prisons by behavioural mimicry. Naturwissenschaften 89: 326-328.

Ellis, J. D., R. Hepburn, K. S. Delaplane, P. Neumann, and P. J. Elzen. 2003. The effects of adult small hive beetles, Aethina tumida (Coleoptera: Nitidulidae), on nests and flight activity of Cape and European honey bees (Apis mellifera). Apidologie 34: 399-408.

El-Niweiri, M.A.A., M. S. El-Sarrag, and P. Neumann. 2008. Filling the Sudan gap: the northernmost natural distribution limit of small hive beetles. J. Apic. Res. 47: 183-184.

Elzen, P. J., J. R. Baxter, P. Neumann, A. Solbrig, C.W.W. Pirk, H. R. Hepburn, D. Westervelt, and C. Randall. 2001. Behaviour of African and European subspecies of Apis mellifera toward the small hive beetle Aethina tumida. J. Apic. Res. 40: 40-41.

Hepburn, H. R., and S. E. Radloff. 1998. Honeybees of Africa. Springer, Berlin, Germany.

Hood, W. M. 2000. Overview of the small hive beetle, Aethina tumida, in North America. Bee World 81: 129-137.

Kovak, H., and K. Crailsheim. 1988. Lifespan of Apis mellifera carnica Pollm. infested by Varroa jacobsoni Oud. in relation to season and extent of infestation. J. Apic. Res. 27: $230-238$.

Lundie, A. E. 1940. The small hive beetle Aethina tumida. Science Bulletin 220. Department Agriculture Forestry, Government Printer, Pretoria, South Africa.

Mürrle, T. M., and P. Neumann. 2004. Mass production of small hive beetles (Aethina tumida Murray, Coleoptera: Nitidulidae). J. Apic. Res. 43: 144-145.

Moritz, R.F.A., and E. E. Southwick. 1992. Bees as superorganisms: an evolutionary reality. Springer, Berlin, Germany.

Neumann, P., and P. J. Elzen. 2004. The biology of the small hive beetle (Aethina tumida Murray, Coleoptera: Nitidulidae): gaps in our knowledge of an invasive species. Apidologie 35: 229-247.
Neumann, P., and J. D. Ellis. 2008. The small hive beetle (Aethina tumida Murray, Coleoptera: Nitidulidae): distribution, biology and control of an invasive species. J. Apic. Res. 47: 180-183.

Neumann, P., C.W.W. Pirk, H. R. Hepburn, A. J. Solbrig, F.L.W. Ratnieks, P. J. Elzen, and J. R. Baxter. 2001. Social encapsulation of beetle parasites by Cape honeybee colonies (Apis mellifera capensis Esch.). Naturwissenschaften 88: 214-216.

Owens, C. D. 1971. The thermology of wintering honey bee colonies. U.S. Dep. Agric. Tech. Bull. 1429: 1-32.

Pettis, J. S., and H. Shimanuki. 2000. Observations on the small hive beetle, Aethina tumida Murray, in the United States. Am. Bee J. 140: 152-155.

Ritter, W. 1982. Experimenteller Beitrag zur Thermoregulation des Bienenvolkes (Apis mellifera L.). Apidologie 13: $169-195$.

Ritter, W. 1996. Diagnostik und Bekämpfung der Bienenkrankheiten. Gustav Fischer, Jena, Germany.

Ritter, W., W. Kerkhof, and S. Pätzold. 1989. The distribution of Varroa jacobsoni Oud. in the winter cluster of Apis mellifera carnica, pp. 107-112. In R. Cavalloro (ed.), Present status of varroatosis in Europe and progress in the Varroa mite control. Commission of the European communities, Brussels, Luxembourg.

Rosenkranz, P., P. Aumeier, and B. Ziegelmann. 2010. Biology and control of Varroa destructor. J. Invertebr. Pathol. 103: 96-119.

Ruttner, F., and H. Hänel. 1992. Active defense against Varroa mites in a Carniolan strain of honey bee (Apis mellifera carnica). Apidologie 23: 173-187.

Sammataro, D., U. Gerson, and G. R. Needham. 2000. Parasitic mites of honey bees: life history, implications and impact. Annu. Rev. Entomol. 45: 517-546.

Sammataro, D., N. Ostiguy, and M. Frazier. 2002. How to use an IPM sticky board to monitor Varroa levels in honey bee colonies. Am. Bee J. 142: 363-366.

Schäfer, M., W. Ritter, J. S. Pettis, and P. Neumann. 2010. Winter losses of honeybee colonies (Hymenoptera: Apidae): The role of infestations with Aethina tumida (Coleoptera: Nitidulidae) and Varroa destructor (Parasitiformes: Varroidae). J. Econ. Entomol. 103: 10-16.

Schulz, A. E. 1984. Reproduktion und Populationsentwicklung der parasitischen Milbe Varroa jacobsoni Oud. in Abhängigkeit vom Brutzyklus ihres Wirtes Apis mellifera L. Apidologie 15: 401-420

Seeley, T. D. 1985. Honeybee ecology: a study of adaptation in social life. Princeton University Press, Princeton, NJ.

Southwick, E. E. 1982. Metabolic energy of intact honey bee colonies. Comp. Biochem. Physiol. A 71: 277-281.

Southwick, E. E. 1983. The honeybee cluster as an homeothermic superorganism. Comp. Biochem. Physiol. A 75: 641-645.

Southwick, E. E. 1985. Allometric relations, metabolism and heat conductance in clusters of honey bees at cool temperatures. J. Comp. Physiol. B 156: 143-149.

Stabentheiner, A., H. Pressl, T. Papst, N. Hrassnigg, and K. Crailsheim. 2003. Endothermic heat production in honeybee winter clusters. J. Exp. Biol. 206: 353-358.

Williams, J. B., S. P. Roberts, and M. M. Elekonich. 2008. Age and natural metabolically-intensive behaviour affect oxidative stress and antioxidant mechanisms. Exp. Gerontol. 43: 538-549.

Received 15 September 2010; accepted 1 March 2011. 